\title{
ACroAngiodermatitis in A LEG AMPUTEE USING A SUCTION-SOCKET PROSTHESIS: CLINICAL, HISTOLOGICAL AS WELL AS HHV-8 AND CD34 IMMUNOHISTOCHEMICAL STUDY
}

\author{
Pawee Pietkiewicz ${ }^{1}$, Monika Bowszyc-Dmochowska ${ }^{1}$, Justyna Gornowicz-Porowska ${ }^{1}$, \\ Przemysław Majewski ${ }^{2}$, Andrzej MarszaŁeK ${ }^{3,4}$, Marian Dmochowski $^{1}$
}

\author{
${ }^{1}$ Cutaneous Histopathology and Immunopathology Section, Department of Dermatology, Poznan University of \\ Medical Sciences, Poznań, Poland \\ 2Department of Clinical Pathomorphology, Poznan University of Medical Sciences, Poznań, Poland \\ 3Department of Tumor Pathology, Poznan University of Medical Sciences, Poznań, Poland \\ 4Department of Clinical Pathomorphology, Collegium Medicum in Bydgoszcz, Nicolaus Copernicus University, Toruń, \\ Poland
}

\begin{abstract}
Acroangiodermatitis (AAD) is a rare, vascular phenomenon of unclear pathogenesis. Itchy, lichenoid, purple/violaceous/yellowish/brownish papules/nodules, plaques/patches mainly on lower limbs occasionally evolve into verrucous lesions and recurrent painful ulcerations. Elevated vein and capillary pressure due to the subatmospheric suspension system seems to be the triggering factor for angioproliferation in the amputation stump. A middle-aged male amputee, a suction-socket prosthesis user, showing combined clinical, histological and immunohistochemical (HHV-8 negative; CD34 and CD31 expressed in endothelial, but not perivascular, cells) features of AAD is presented. Dermatologists, orthopedic surgeons, pathomorphologists, but also prosthesis makers and amputees themselves, should be aware of AAD as suction-socket prostheses become increasingly popular.
\end{abstract}

Key words: acroangiodermatitis, prosthesis, amputation stump.

\section{Introduction}

Acroangiodermatitis (pseudo-Kaposi sarcoma, AAD) is a rare, chronic vascular phenomenon of unclear pathogenesis described by Mali et al. in 1965 [1, 2]. The disease might be congenital, yet in acquired form chronic venous insufficiency and vascular anomalies seem to be an underlying background for proliferation of preexisting blood vessels. The AAD was reported in patients with paralyzed limbs [3], hemodialysis patients with arteriovenous shunts [4] or after minor trauma [5] as well as in amputees with suction-socket prostheses $[6,7]$.

Although vascular hyperplasia, blood extravasation leading to hemosiderin deposition and inflammatory infiltration are features of both AAD and Kaposi sarcoma (KS), both entities remain unrelated, despite the fact that a relationship might be suspected on the basis of misleading nosology proposed by Earhart et al. [2]. Kaposi sarcoma is a progressive cancer of endothelial origin that may imitate AAD clinically and even histopathologically. Regardless of histopathological features that may be utilized to distinguish these angioproliferative disorders (a lobular arrangement of blood vessels with thick walls and "chubby" endothelial cells, absence of cell atypia and lesser inflammatory infiltrate that is generally poor in plasma cells in AAD), immunostaining for the CD34 antigen as well as tissue, most importantly, and blood studies for Kaposi's sarcoma-associated herpesvirus (HHV-8) were adopted to differentiate these entities of significantly distinct prognosis [8-10]. Other methods of distinction may be CD31-immunolabelling, endothelial cell markers 
UEA-1 and factor VIII, or radiological imaging (ultrasonography, Doppler ultrasound, magnetic resonance tomography, computed tomography, angiography and phlebography) [4, 11-13]. The first suctionsocket prosthesis was invented by Dubois D. Parmelee in 1863. In the fourth decade of the twentieth century that type of prosthesis was reintroduced for war amputees. The prosthesis holds the amputation stump by anatomical adjustment and by suction created by an air-tight socket that prevents rotation. Elevated vein and capillary pressure due to the sub-atmospheric suspension system seems to be the triggering factor for angioproliferation.

We report a case of a male amputee, using a suction-socket prosthesis, with combined clinical, histopathological and immunohistochemical features of AAD.

\section{Case report}

A 50-year-old male truck driver presented with itchy blue-purple papulo-erythematous lichenoid lesions on the amputation stump (Fig. 1A). Above-knee amputation was performed a year before due to crushing trauma of the left lower limb. The lesion appeared primarily as an erythematous macule after half-year usage of a suction-socket prosthesis. The patient was consulted by the angiologist two weeks before admission and had Doppler ultrasound of limb vessels performed, finding neither vascular nor blood flow disorder. Laboratory tests were normal (including $\mathrm{HBV}$ and $\mathrm{HCV}$ testing). Epicutaneous patch tests with European Standard Series and Extended Orthopedic Series (a total of 63 allergens) were performed to rule out allergic contact dermatitis to prosthesis material, yet all were negative at 48 and 72 hours. Histopathology of the lesional skin (hematoxylin and eosin staining) (Fig. 1C) revealed a lobular arrangement of proliferating blood vessels with thick walls and "chubby" endothelial cells, marked erythrocyte extravasation and hemosiderin deposits in the upper half of the dermis with inconspicuous inflammatory cells. Blood study for HHV-8 DNA as well as immunostaining on a paraffin block slide with mouse monoclonal antibody (13B10) against HHV8 latent nuclear antigen-1 (LNA-1) (Fig. 1D) was negative. The vessels showed regularity and there was neither endothelial nor epithelial atypia present. CD34 (Fig. 1E) and CD31 (Fig. 1F) expression in plump endothelial cells, but not in perivascular cells, in blood vessels of the papillary dermis was revealed with immunohistochemical staining. Thus, the patient presented clinical, histopathological and immunopathological features which considered together enabled the diagnosis of suction-socket prosthesis-associated AAD. The patient was advised to have his suspension type prosthesis replaced with a strap-suspension system retaining other functional modules and treated topically with clobetasol pro- pionate ointment initially and then tacrolimus ointment. After 6-month follow-up, an improvement of the clinical picture was noted (Fig. 1B).

\section{Discussion}

The renaissance of suction-socket prostheses began in the fourth decade of the previous century. The dermatological problems of amputees may be caused by contact dermatitis, poor hygiene of the stump, mechanical microtrauma and, last but not least, the prosthesis suspension mechanism. Despite the embarrassing fart-like sound during readying for use and poor fit (probably due to maladaptation), our patient opted for this suspension type, as it seemed to him comfortable for everyday use. Interestingly, the price of the expensive modular prosthesis bought by the patient was equivalent to about eight mean monthly incomes in Poland at the end of 2011 and Poland's National Health Fund covered just slightly above $10 \%$ of the costs. Recently, there has been some debate whether sub-atmospheric socket prostheses can be used in patients with vascular amputation. Production of a thigh-fit socket is difficult artisan-like work as acquiring proper adjustment frequently means repetition of the whole process. Unnecessary air chambers and poor fitting favor impairment of blood supply of the stump that results in bruising/violaceous discoloration. In the case reported here, the prosthesis using the sub-atmospheric suspension system plausibly led to development of AAD by evoking superficial venous stasis in the amputation stump, resulting in pathological reactive angiogenesis and fibrosis.

In the context of $\mathrm{AAD}$ ruling out $\mathrm{KS}$ is essential since both entities have different prognosis and treatment methods. Obviously, the expression of CD34 and CD31 in endothelial cells of blood vessels is not an extraordinary finding; nevertheless, the expression pattern of these proteins $[14]$ considered not separately but in conjunction with remaining clinical (particularly improvement of lesions after prosthesis change), microscopic and laboratory data, together with tissue and blood HHV-8 evaluation [15], enabled the diagnosis of AAD in the case presented here.

Over 100 cases of AAD have been described in adults, making this disease rare, yet not exceptional. Nonetheless, the association with suction-socket prostheses is mentioned in just a tiny fraction of published AAD cases, making such an association still infrequent. As some authors recommend suction-socket prostheses also in children as young as 5 years of age [16], it seems imaginable that AAD lesions might appear in both pre-adolescent and adolescent amputees as the child's growing body should be taken into consideration. In both children and adults neovascularization is mediated by intertwined molecular pathways mediated by VEGF, bFGF, angiopoietins, ephrins, and class 3 

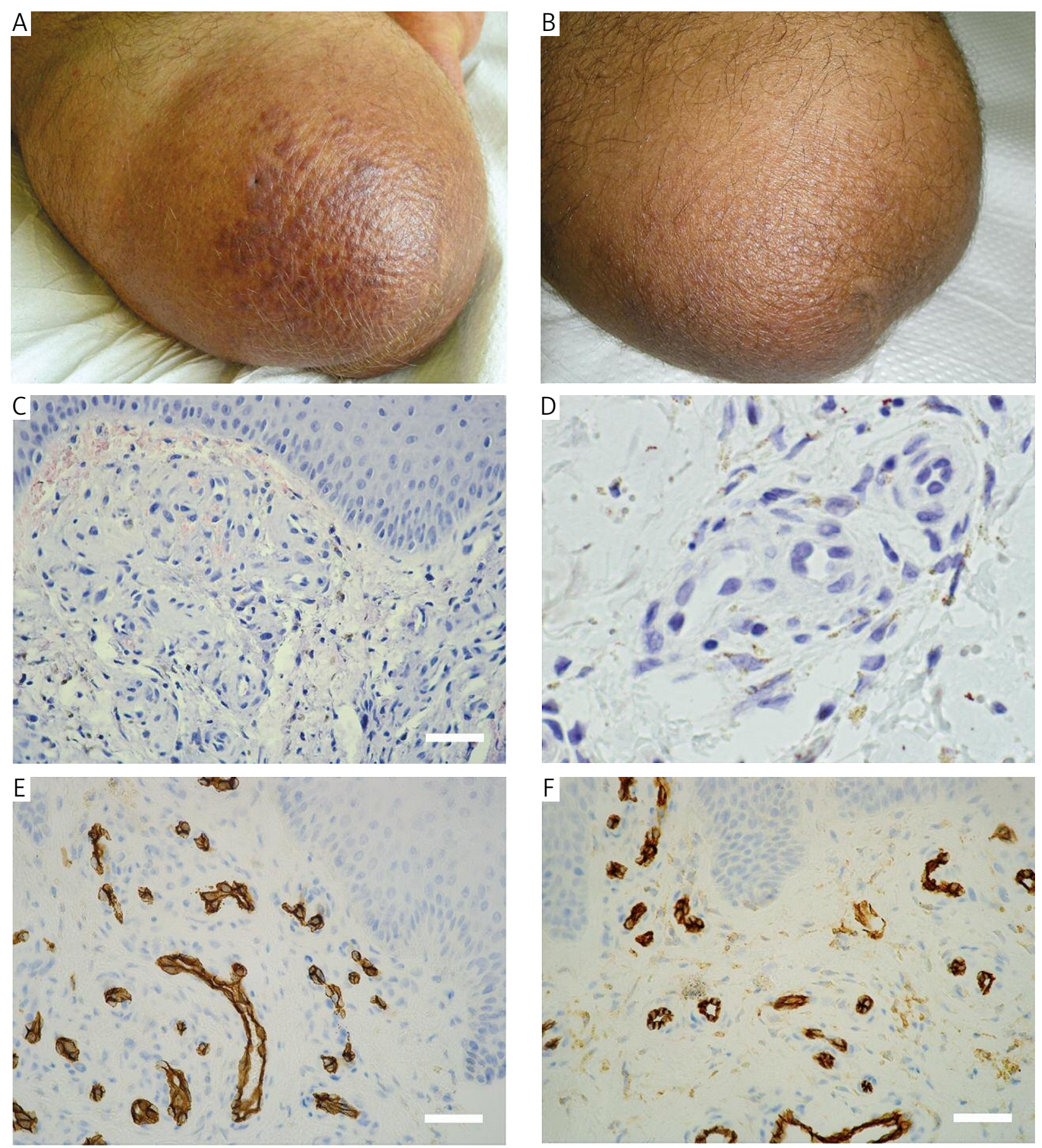

Fig. 1. Violaceous/brownish lichenoid lesions on the amputation stump of the leg. Biopsy site on the medial/frontal aspect of the thigh. The patient was referred by Leszek Bartoszak $\mathrm{MD} / \mathrm{PhD}(\mathbf{A})$. Remission of stump lesions after 6month follow-up period (B). Proliferation of blood vessels, in lobular pattern, with thick walls and "chubby" endothelial cells and marked erythrocyte extravasation and hemosiderin deposits in the papillary dermis without either endothelial or epithelial atypia and inconspicuous inflammatory infiltrate (HE staining, original magnification $400 \times$, bar $=50 \mu \mathrm{m}$ ) (C). Immunohistochemical evaluation for HHV-8 - negative result (mouse monoclonal antibody (13B10) against HHV-8 latent nuclear antigen-1, LNA-1, primary objective magnification 40×) (D). CD34 (E) and CD31 (F) expression in "chubby" endothelial cells, but not in perivascular cells, in blood vessels of the papillary dermis (immunohistochemical staining, original magnifications $400 \times$, bar $=50 \mu \mathrm{m}$ )

semaphorins [17], which conceivably might be targets for AAD-oriented therapeutic intervention.

As realities in former Soviet bloc countries were unfavorable for both international scientific exchange and availability of foreign language dermatology textbooks, $\mathrm{AAD}$ was neglected in Polish dermatological literature until the end of the $20^{\text {th }}$ century $[18,19]$. Hence, middle-aged and elderly Polish dermatologists who had ac- 
cess to just native literature might misdiagnose and presumably underdiagnose AAD. Ironically, many international journals continue to require purchasing online access, and open access is still uncommon, making accessibility to professional knowledge difficult even nowadays, especially for junior physicians. Thus, this case report was conceived within a framework of the continuing medical self-education to increase awareness of AAD among dermatologists, orthopedic surgeons, pathomorphologists, but also prosthesis makers and amputees themselves, regardless of their age and nationality, as suction-socket prostheses become increasingly popular.

The authors declare no conflict of interest.

\section{References}

1. Mali JW, Kuiper JP, Hamers AA. Acro-angiodermatitis of the foot. Arch Dermatol 1965; 92: 515-518.

2. Earhart RN, Aeling JA, Nuss DD, et al. Pseudo-Kaposi sarcoma. A patient with arteriovenous malformation and skin lesions simulating Kaposi sarcoma. Arch Dermatol 1974; 110: 907-910.

3. Landthaler M, Langehenke H, Holzmann H, et al. Mali's acroangiodermatitis (pseudo-Kaposi) in paralyzed legs. Hautarzt 1988; 39: 304-307.

4. Fernández R, Verea MM, Martínez W, et al. Bilateral pseudoKaposi sarcoma in upper limbs. Actas Dermosifiliogr 2007; 98: 268-270.

5. Del-Río E, Aguilar A, Ambrojo P, et al. Pseudo-Kaposi sarcoma induced by minor trauma in a patient with Klippel-TrenaunayWeber syndrome. Clin Exp Dermatol 1993; 18: 151-153.

6. Meulenbelt HE, Geertzen JH, Dijkstra PU, et al. Skin problems in lower limb amputees: an overview by case reports. J Eur Acad Dermatol Venereol 2007; 21: 147-155.

7. Virgili A, Trincone S, Zampino MR, et al. Acroangiodermatitis of amputation stump. Eur J Dermatol 2003; 13: 402-403.

8. Kanitakis J, Narvaez D, Claudy A. Expression of the CD34 antigen distinguishes Kaposi's sarcoma from pseudo-Kaposi's sarcoma (acroangiodermatitis). Br J Dermatol 1996; 134: 44-46.

9. Cheuk W, Wong KO, Wong CS, et al. Immunostaining for human herpesvirus 8 latent nuclear antigen- 1 helps distinguish $\mathrm{Ka}$ posi sarcoma from its mimickers. Am J Clin Pathol 2004; 121: 335-342.

10. Ganem D. KSHV and the pathogenesis of Kaposi sarcoma: listening to human biology and medicine. J Clin Invest 2010; 120: 939-949.

11. Brenner S, Martinez de Morentin E. What's new in pseudo-Kaposi's sarcoma. J Eur Acad Dermatol Venereol 2001; 15: 382-384

12. Russell Jones R, Orchard G, Zelger B, et al. Immunostaining for CD31 and CD34 in Kaposi sarcoma. J Clin Pathol 1995; 48: 1011-1016.

13. Pimentel MI, Cuzzi T, Azeredo-Coutinho RB, et al. Acroangiodermatitis (pseudo-Kaposi sarcoma): a rarely recognized condition. A case on the plantar aspect of the foot associated with chronic venous insufficiency. An Bras Dermatol 2011; 86 (4 Suppl 1): S13-6

14. Rosado FG, Itani DM, Coffin CM, et al. Utility of immunohistochemical staining with FLI1, D2-40, CD 31, and CD 34 in the diagnosis of acquired immunodeficiency syndrome-related and non-acquired immunodeficiency syndrome-related Kaposi sarcoma. Arch Pathol Lab Med 2012; 136: 301-304.

15. Tchernev G, Patterson JW, Ananiev J, et al. Unilateral presentation of pseudo-Kaposi's acroangiodermatitis - a diagnostic and therapeutic challenge. Vojnosanit Pregl 2012; 69: 370-373.
16. Krebs DE, Edelstein JE, Thornby MA. Prosthetic management of children with limb deficiencies. Phys Ther 1991; 71: 920-934.

17. Conrotto P, Valdembri D, Corso S, et al. Sema4D induces angiogenesis through Met recruitment by Plexin B1. Blood 2005; 105 11: 4321-4329.

18. Kondratowicz A, Woźniak Z, Pluciński P. Acroangiodermatitis (pseudo-Kaposi sarcoma) in a leg amputation stump - case report. Przegl Dermatol 2004; 3: 229-232.

19. Mikulska D, Maleszka R, Dziuba I, et al. Pseudosarcoma Kaposi (acroangiodermatitis) - a case report. An application of thermography in diagnostics. Dermatol Klin 2006; 8: 41-44.

\section{Address for correspondence}

Assoc. Prof. Marian Dmochowski MD/PhD

Cutaneous Histopathology and Immunopathology Section

Department of Dermatology

Poznan University of Medical Sciences

Przybyszewskiego 49

60-355 Poznań, Poland

tel. +4861 8691319

e-mail:mkdmoch@wp.pl 